\section{Risks of cardiac imaging}

With regard to the research article by Eisenberg and colleagues, ${ }^{1}$ the authors only briefly note that the radiationassociated increase in cancer risk is higher than for atomic bomb survivors in the Life Span Study (LSS). ${ }^{2}$ In the LSS, the excess relative risk per sievert (Sv) for the group exposed at 40 years or older is about 0.25 , which would correspond with a $0.25 \%$ increase in cancer risk per $10 \mathrm{mSv} ;^{2}$ the CMAJ publication finds a $3 \%$ increased risk per $10 \mathrm{mSv}$ for patients exposed at a similar age. The LSS data given are for cancer mortality whereas the current study is for cancer incidence, but effects of radiation on cancer incidence are only slightly higher than those for cancer mortality. ${ }^{3}$ Could the authors comment in more detail?

\section{David A. Toms MD}

Semiretired radiologist, Charlottetown, PEI

\section{References}

1. Eisenberg MJ, Afilalo J, Lawler PR, et al. Cancer risk related to low-dose ionizing radiation from cardiac imaging in patients after acute myocardial infarction. CMAJ 2011;183:430-6.

2. National Research Council of the National Academies, Committee to Assess Health Risks from Exposure to Low Levels of Ionizing Radiation. Biological effects of ionizing radiation - BEIR VII phase 2. Washington (DC): National Academies Press; 2006. p. 146.

3. National Research Council of the National Acade mies, Committee to Assess Health Risks from Exposure to Low Levels of Ionizing Radiation. Biological effects of ionizing radiation - BEIR VII phase 2. Washington (DC): National Academies Press; 2006. p. 144-5.

\section{CMAJ 2011. DOI:10.1503/cmaj.111-2086}

\section{The authors respond:}

We thank Dr. Toms for his interest in our work. ${ }^{1}$ We would like to point out, however, that several important considerations limit his comparison of the data. First, the Life Span Study (LSS) findings for "lifetime risk" that he cites are for cancer mortality and not cancer incidence, which we report. ${ }^{2-4}$ Cancer incidence and mortality are not equivalent, and therefore direct comparison is inappropriate. Attempts to compare incidence and mortality from the LSS cohort, which began in 1950, are difficult because improved diagnosis and treatment have led to changes in cancer mortality over time. Additionally, the lifetime risk that Dr. Toms cites is for 50 -year-old men from LSS. Women have higher cancer risks associated with radiation exposure. ${ }^{3}$ Given that about one-third of our cohort were women, the numbers cited by Dr. Toms likely underestimate the magnitude of risk that would be expected in our study. Furthermore, Dr. Toms cites lifetime risk, which attempts to incorporate the observation that age and sex affect the magnitude of risk associated with low-dose ionizing radiation exposure. Lifetime risks in LSS were estimated using lifetable calculations based on background cancer rates and all-cause death rates, and are not easily generalizable to populations in a different time and place. ${ }^{3}$ Our study describes a medical cohort (not a general population-based cohort, as is included in LSS) with likely a higher prevalence of smoking and obesity - risk factors for both coronary artery disease and cancer compared with the general population.

That being said, the degree of difference between our estimates and those from LSS is not dramatic. LSS found an overall excess relative risk (equal to relative risk - 1.0) of about 0.5 per sievert $(\mathrm{Sv})$; in other words, a relative risk of 1.0005 per $\mathrm{mSv}^{3,5}$ We found a hazard ratio of 1.003 per $\mathrm{mSv}$, differing from LSS by a factor of only sixfold. Even when the lifetime risk calculations cited by Dr. Toms are compared (acknowledging that our cohort included a substantial number of women), the risk differs by 10 -fold at most.

LSS included data from 94000 atomic-bomb survivors (and 27000 unexposed people). Our study includes data from almost 83000 people. If there is a small difference (less than 10fold) between the findings from these two cohorts - which themselves have very different demographic compositions - we would submit that the actual rate might be between the two estimates. In other fields of clinical medicine, no one study is relied upon for gold-standard estimates of an outcome - especially a study that examined a very different source of exposure. That this seems to be the case in radiation research concerns us.

\section{Mark J. Eisenberg MD MPH \\ Louise Pilote MD MPH PhD \\ Patrick R. Lawler MD \\ Jonathan Afilalo MD MSc \\ McGill University, Montréal, Que.}

\section{References}

1. Eisenberg MJ, Afilalo J, Lawler PR, et al. Cancer risk related to low-dose ionizing radiation from cardiac imaging in patients after acute myocardial infarction. CMAJ 2011;183:430-6.

2. National Research Council of the National Academies, Committee to Assess Health Risks from Exposure to Low Levels of Ionizing Radiation. Biological effects of ionizing radiation - BEIR VII phase 2. Washington (DC): National Academies Press; 2006. p. 145.

3. Preston DL, Shimizu Y, Pierce DA, et al. Studies of mortality of atomic bomb survivors. Report 13: Solid cancer and noncancer disease mortality: 1950-1997. Radiat Res 2003;160:381-407.

4. Eisenberg MJ, Afilalo J, Lawler PR, et al. Cancer risk related to low-dose ionizing radiation from cardiac imaging in patients after acute myocardial infarction. CMAJ 2011;183:430-6.

5. Radiation Effects Research Foundation. Available: www.rerf.or.jp/radefx/late_e/cancrisk.html.

CMAJ 2011. DOI:10.1503/cmaj.111-2087

\section{Letters to the editor}

In submitting a letter, you automatically consent to have it appear online and/or in print. All letters accepted for print will be edited by $C M A J$ for space and style. Most references and multiple authors' names, full affiliations and competing interests will appear online only. (The full version of any letter accepted for print will be posted at cmaj.ca.) 